\title{
AIRCRAFT LIGHTNING PROTECTION DESIGN AND CERTIFICATION STANDARDS
}

\author{
J. Anderson Plumer \\ Iightning Technologies, Inc. \\ 10 Downing Parkway \\ Pittsfield, MA 01201 \\ U.S.A.
}

\section{INTRODUCTION}

U.S. standards which describe the lightning environment for use in design and certification of lightning protection for aircraft are published in U.S. Federal Aviation Administration (FAA) Advisory Circulars 20-53A for lightning direct (physical damage) effects and in AC 20-136 for indirect effects (induced transients). These standards are intended to describe the electric fields that surround an aircraft during strike attachment and the currents that flow through an aircraft during in-flight lightning strikes. They are parameters that can be produced by high voltage and high current generators for protection design and certification tests of aircraft components and systems, and are based on characteristics of cloud-to-earth as well as intra-cloud flashes. Because of the requirement that the standard lightning parameters be reproducible by laboratory test generators, certain compromises have been necessary in their definitions, and they are thus not fully representative of the natural lightning parameters they represent. In most cases, the effects of the standardized lightning test waveforms on aircraft structures and components are very similar to the effects of natural lightning electric fields and currents. In a few cases, which are discussed herein, some natural lightning effects are thought not to be fully represented. The standards are being continually updated to reflect advances in knowledge of pertinent aspects of lightning phenomenology.

\section{BACKGROUND}

Internationally accepted standards for use in evaluating lightning effects on electric power transmission and distribution systems have existed for a long time $[1,2]$. These, however, represent the surge voltages that appear on transmission lines and at insulators and terminal equipment, and the currents that flow to earth in surge arresters. Therefore, their amplitudes and time histories (waveshapes) are based on the responses of power transmission systems to lightning strikes, not the natural lightning characteristics themselves. By the time aircraft lightning tests became necessary (1940-1960) most lightning test facilities were configured to reproduce the power industry standard voltages and currents, and not those of natural lightning. It was, however, those laboratories which were looked to for early aircraft lightning tests, and these tests often involved application of the power industry standards to aircraft.

One of the first aircraft test standards was a unidirectional current pulse intended to represent a first return stroke, rising to a peak of 
$200 \mathrm{kA}$ and decaying to $50 z$ of peak in $50 \mu \mathrm{s} \mathrm{[3];} \mathrm{similar} \mathrm{to} \mathrm{a} \mathrm{double}$ exponential, though not precisely defined as such. This was intended to represent a severe first return stroke, which also had a rate of change $(d i / d t)$ of $10^{11} \mathrm{~A} / \mathrm{s}$, though the time duration of this rate of change was not defined. Another early aircraft standard [4] included a continuing current of $200 \mathrm{~A}$ for a period of $1 \mathrm{~s}$. There were no electric field or high voltage waveforms incorporated in these early standards. Unfortunately, none of the laboratories could produce a unidirectional current waveform of $200 \mathrm{kA}$ amplitude, as such circuits require excessive resistances and very high charging voltages.

of necessity, aircraft tests were conducted with available generators, typically of 20-30 $\mu \mathrm{F}$, discharging through low resistances so that required peak amplitudes could be reached. This resulted in damped sinusoid instead of unidirectional current waveforms being applied. The frequency and decrement of these test waveforms was largely dependent upon the generator capacitances and test circuit inductance parameters that could not easily be varied. To achieve the desired current amplitudes, total test circuit resistance was in most cases limited to $50 \times 10^{-3} \mathrm{ohms}$. The result was that test currents of widely varying frequencies and decay times were applied, dependent on existing laboratory generator capacitance and test specimen impedance.

This situation was tolerated during the days of all-metal aircraft, when primary interest was centered upon superficial effects such as arcing at structural joints and shock or blast wave effects; however, damage to carbon fiber composite (GFC) skins and structures is more closely related to the action integral $\left(f_{i}(t)^{2} d t\right)$ of the test current, and induced transients are dependent upon its rates of change and time duration. For example, the thermal energy, $w$, dissipated in a resistive material by electric current is

$$
W=\int \dot{i}(t)^{2} d t \cdot R
$$

where

$$
\begin{aligned}
\int i(t)^{2} d t & =\text { current action integral } \\
R & =\text { test specimen resistance }
\end{aligned}
$$

In 1972 a subcommittee which is known today as SAE Committee AE4L (Lightning) was formed to update the aircraft lightning protection design and test standards. During the period 1975 through 1987 this committee published the present aircraft lightning standards in a series of committee reports $[5,6]$. These standards were subsequently adopted by U.S. civil and military authorities $[7,8,9]$.

\section{BASIS FOR THE AIRCRAFT LIGHTNING STANDARDS}

The aircraft lightning standards as described in $[5,7]$ are based on the characteristics of severe positive and negative cloud-to-earth flashes as described by Cianos and Pierce [10] and, more recently, by Andersen and Eriksson [11]. These references provide statistical distributions of cloud-to-earth lightning characteristics including peak amplitudes, rise 
and decay times, rates of rise of first and subsequent stroke currents, amplitudes and charge tranfers of continuing currents, and numbers of strokes in a flash. The standards include four voltage waveforms that represent the electric field immediately adjacent to the airplane during the lightning attachment phase, plus a group of four current components representing the important effects of a severe cloud-to-earth lightning flash. The voltage and current waveforms that comprise lightning standards for aircraft direct effects protection design and testing are shown in Figures 1 and 2. The individual waveforms or components and the lightning characteristics each is derived from are as follows:

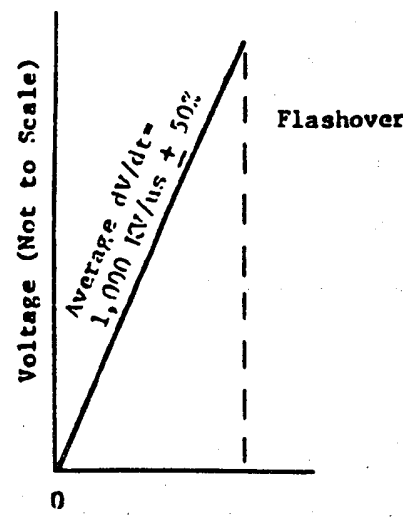

Voltage Waveform A

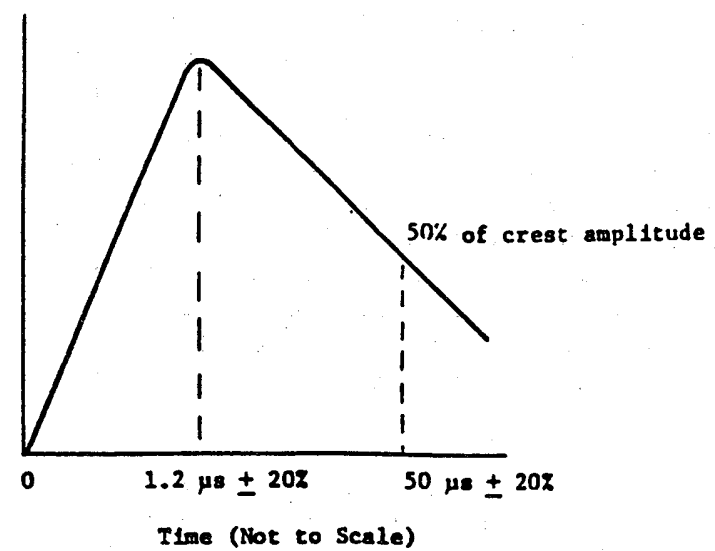

Voltage Waveform B

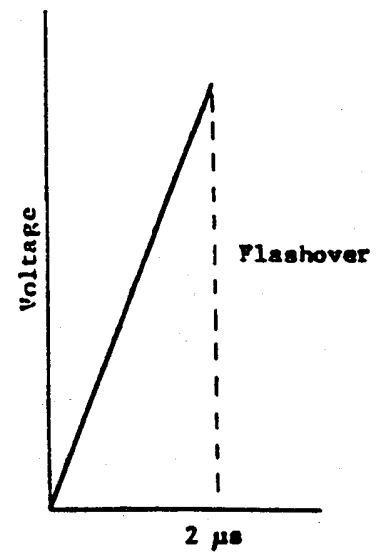

Voltage Waveform C

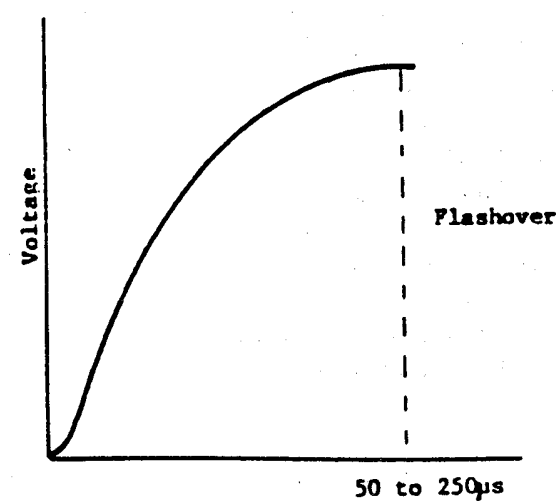

Voltage Waveform D

Figure 1 - Aircraft Standard Voltage Waveforms 


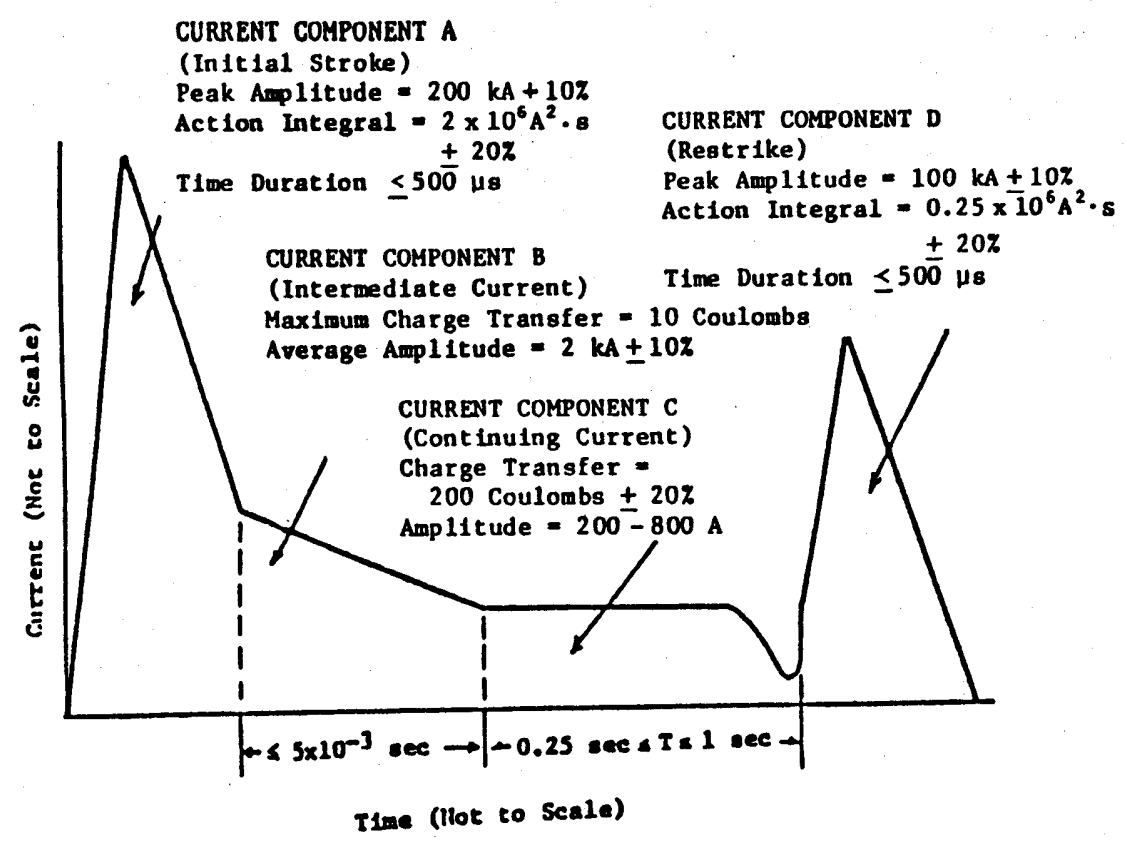

Idealized Current Test Waveform Components for Qualification Testing

Figure 2 - Aircraft Standard Current Waveforms for Direct Effects (Components A, B, C and D)

\section{VOLTAGE WAVEFORMS}

Voltage Waveform A - Basic lightning voltage. This waveform, which rises to flashover of the electrode-to-specimen gap at a near constant rate of $1,000 \mathrm{kV} / \mu \mathrm{s}$, is intended to represent the electric field at aircraft extremities when an approaching lightning leader is sufficiently close to an aircraft to produce streamer and junction leader formation from the extremities; or, in the event no natural leader is present, to promote initial leader formation at the aircraft extremities. This field is of sufficient intensity to cause rapid breakdown and puncture of some dielectric materials such as fiberglass or aramid fiber-reinforced plastic materials as used in radomes, wing tips, antenna covers; and of glass or polycarbonate resin transparencies which are occasionally punctured by inflight lightning strikes.

The waveform A parameters were selected from laboratory test conditions that seemed to best replicate in-flight puncture vs. flashover experience. Factors known to determine whether puncture or surface flashover of dielectrics will occur in laboratory tests include electrode geometry and voltage rate of rise (dv/dt) to gap flashover. In most cases, slowly rising fields are more likely to cause flashover of external surfaces, whereas more rapidly rising fields result in punctures. A "slow" rising field may reach $500 \mathrm{kV} / \mathrm{m}$ in $750 \mu \mathrm{s}$ and surface flashover, whereas an "overvoltaged" gap reaching $1,300 \mathrm{kV}$ in $<2 \mu \mathrm{s}$ will cause puncture (if puncture is at all possible). The $1,000 \mathrm{kV} / \mu \mathrm{s}$ linear rising "front of 
wave" voltage applied for power system lightning arrester tests has seemed to best replicate aircraft puncture vs. flashover experience in laboratory tests at flight altitudes, these voltages would be lower in accordance with ionization potentials of air at lower pressures, so that the percentages of surface flashovers (in air) at flight altitudes would be greater than at sea level (breakdowns of most "solid" dielectrics are less related to air pressure).

Voltage Waveform B - Full voltage waveform. This is intended to represent the E-field about other surfaces of the aircraft which are not likely to produce junction leaders, but which may experience temporary ionization until extremity fields collapse at lightning leader attachment. Waveform B also represents the aircraft potential rise when return stroke currents pass through the aircraft. The waveform is usually applied from a blunt or Rogowski-shaped electrode which promotes corona and streamer growth at the test object surface prior to streamer formation at the electrode. The test voltage is removed prior to complete flashover of the gap. For convenience, waveform $B$ is also the power-industry standard $1.2 \times$ $50 \mu \mathrm{s}$ dielectric test waveform.

Voltage Waveform c - Voltage waveform for aircraft model tests. Waveform $\mathrm{C}$ has a linear rise to flashover in $2 \mu \mathrm{s}$ for application between a rod electrode simulating an approaching leader and a model airplane suspended between the "leader" and a ground plane, each approximately one leader step distance from the model. The step distances (i.e., striking distances) are scaled in accordance with the model scale factor. Most aircraft lightning test models are $1 / 25$ scale (or smaller) so the $2 \mu s$ flashover time corresponds to a leader pause/step time of $50 \mu \mathrm{s}$.

Voltage Waveform D - Alternate lightning voltage. This waveform increases to gap flashover in times ranging from 50 to $250 \mu \mathrm{s}$ exponentially and is also intended to represent E-fields surrounding aircraft extremities, but for the primary purpose of encouraging streamer and junction leader formation from multiple points on and near an extremity. By not overvoltaging the electrode-specimen gap, this field gives time for coronastreamer-leader formations at less probable attachment points, and so enables these to be discovered in laboratory tests. Examples are surfaces of larger radii of curvature than the outermost extremity, where potentially vulnerable materials and components are sometimes installed in the expectation they are electrostatically shielded or "protected" by the extremity. Occasionally, waveform D causes puncture where A will not: the reason again being additional time for streamer formation from conductors within the dielectric skin.

\section{CURRENT WAVEFORM - DIRECT EFFECTS}

Currents for evaluation of lightning direct (physical damage) effects are defined as individual components of a complete lightning flash waveform, as shown in Figure 2. The components follow directly after each other, but not all of them are applied to each part of an aircraft; their applicability being dependent on aircraft lightning strike zones. None of the components is a faithful reproduction of its natural lightning counterpart, but each contains characteristics that cause important direct effects. Details are as follows: 
Component A - First return stroke. Component A combines the high amplitude of severe negative cloud-earth strokes with the higher action integral of a severe positive stroke. The $200 \mathrm{kA}$ peak amplitude occurs about 0.58 of the time in negative flashes. Statistics of $(+)$ stroke action integrals are less reliable, but $2 \times 10^{6}$ is "severe". Limitations of laboratory impulse current generators and the (convenient) fact that the highest rates of stroke current rise are not found in first return strokes is why rate-of-rise is not specified in component $A$ for direct effects. Component $A$ direct effects on aircraft include blast, shock wave, magnetic force and ohmic heating in materials and arcing at structural joints.

Component B - Intermediate current. Component B accounts for the short duration periods of following current above continuing current amplitudes (i.e., > 1,000 A) in negative flashes, and for the higher amplitude "tail" portion of positive strokes. Thus, Components A and B are always applied together, in all zones, to represent positive stroke effects. Component $B$ delivers $10 \mathrm{c}$ in $5 \mathrm{~ms}$ at an average rate of $2 \mathrm{kA}$, and causes melting of metal surfaces. The combination of amplitude and time duration often make its effects on thin metal skins more damaging than the stroke currents.

Component c - Continuing current. This represents continuing currents in negative cloud-earth flashes and the follow current in positive cloud-earth flashes, and the $200 \mathrm{c}$ charge transfer is representative of severe versions of both, though the percentage of flashes known to exceed this charge is greater than the stroke current percentage basis. Continuing currents above $0.5 \mathrm{~s}$ nearly always occur at aircraft trailing edges, where the melting these currents produce is of little consequence.

Component D - subsequent stroke. Component D represents a severe subsequent stroke in a negative cloud-earth flash. Its amplitude (100 kA) is again at about 0.58 severity, and its action integral $\left(0.25 \times 10^{6} \mathrm{~A}^{2} . \mathrm{s}\right)$ is probably more typical of a combination of subsequent strokes than of one. Whereas most negative cloud-earth flashes have three or more strokes, it would be impractical to include more than one in the aircraft test standards because each stroke requires a separate test generator. This is also unnecessary because except at trailing edges, each stroke arrives at a different spot on an aircraft. It should be noted that the action integral of component $A$ is eight times that of $D$, and most of the direct effects caused by $A$ are greater than those caused by $D$ by a similar amount.

Identification of the aircraft zones within which each of these components occur is therefore of great importance; a topic to be discussed later in this paper.

\section{CURRENT WAVEFORMS - INDIRECT EFFECTS}

Stroke currents $A$ and $D$ and component $H$, which represents a severe intra-cloud current pulse, are applied for evaluation of lightning induced voltage and current transients in aircraft wiring. These components are shown in Figures 3 and 4 . Important aspects of these waveforms are as follows: 


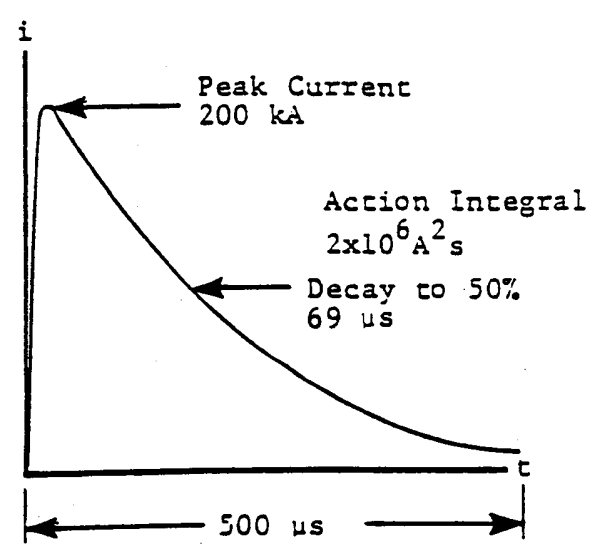

WAVEFORIS

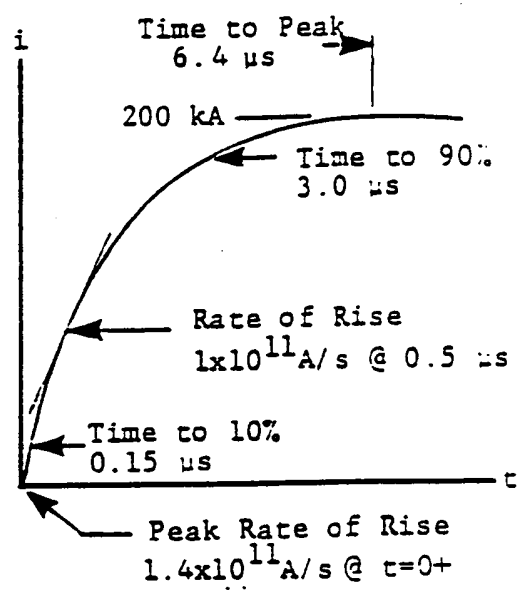

WAVEFRONI

A COPPONENT

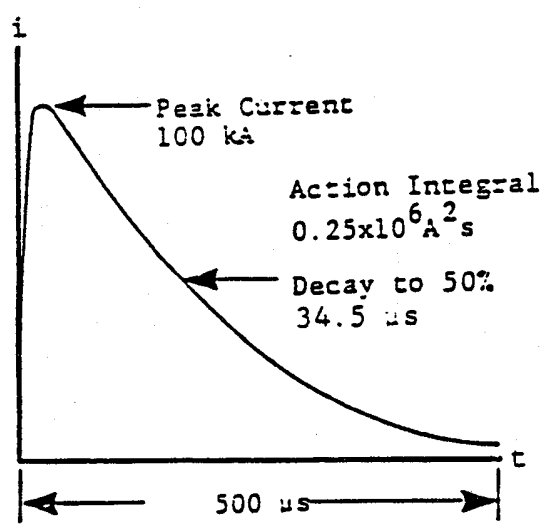

WRVEEORM

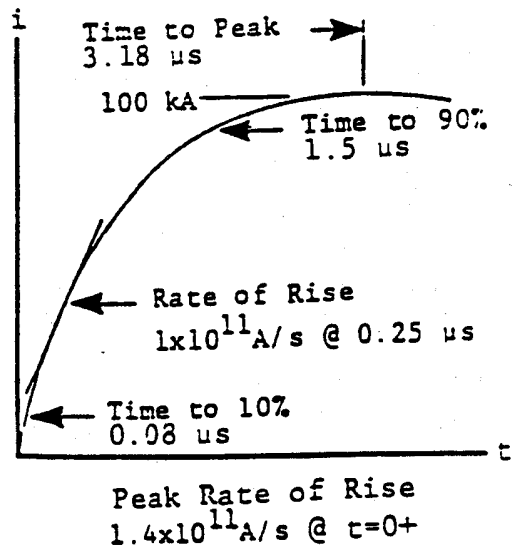

WAVEERONT

D COMPONENT

Figure 3 - Aircraft Standard Current Waveforms for Indirect Effects (Components A, D) 


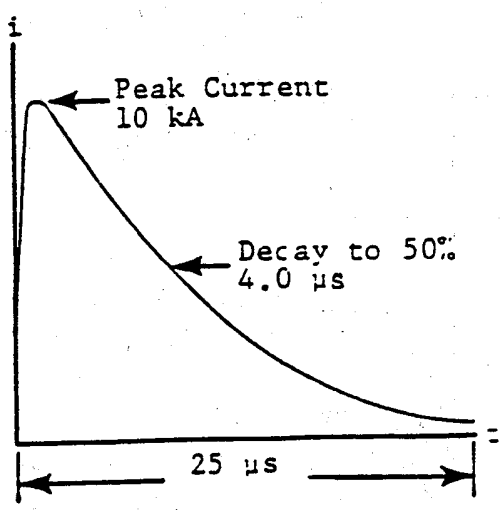

WAVEFORI

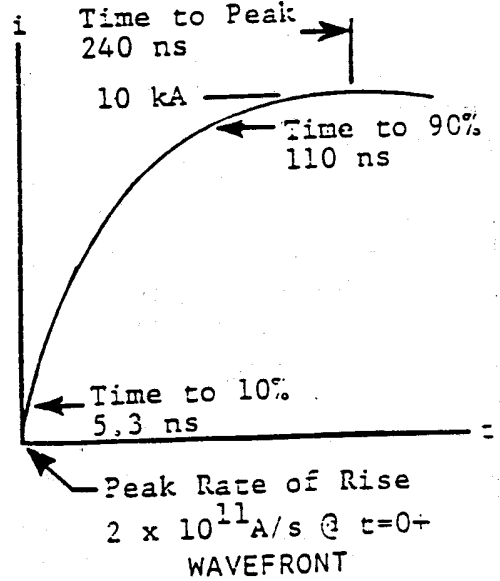

WAVEFRONT

H COPIPONENT

Figure 4 - Aircraft Standard Current Waveforms for Indirect Effects (Component $\mathrm{H}$ )

Components $A$ and $D$ - First and subsequent stroke currents. These have the same parameters as for direct effects evaluations plus defined rates of rise and decay times. The peak and "average" $\mathrm{di} / \mathrm{dt}$ 's of $1.4 \mathrm{x}$ $10^{11} \mathrm{~A} / \mathrm{s}$ and $1.0 \times 10^{11} \mathrm{~A} / \mathrm{s}$ (at $t=0.5$ and $0.25 \mu \mathrm{s}$ for components $\mathrm{A}$ and $\mathrm{D}$, respectively) are based on severe, sustained rates of rise in negative flashes. Whereas higher rates have been recorded, most are of shorter duration. Time duration of $\mathrm{di} / \mathrm{dt}$ is important in determining magnitude of induced currents in aircraft wiring, with induced currents being especially dependent on the time durations of changing currents. The double exponential waveshapes enable high rates of rise to be combined with long decay times, and are mathematically useful for indirect effects analysis purposes while being reproducible by $R-L-C$ test circuits. The double exponential form is more typical of subsequent than of first return strokes in naturally occurring flashes, since the high di/dt portion of a double exponential is at $t=0$ rather than near the first current peak as in natural first return strokes, as illustrated in Fig. 5 . Whereas naturally occurring subsequent strokes usually have higher di/dt's than first strokes, the rates have been

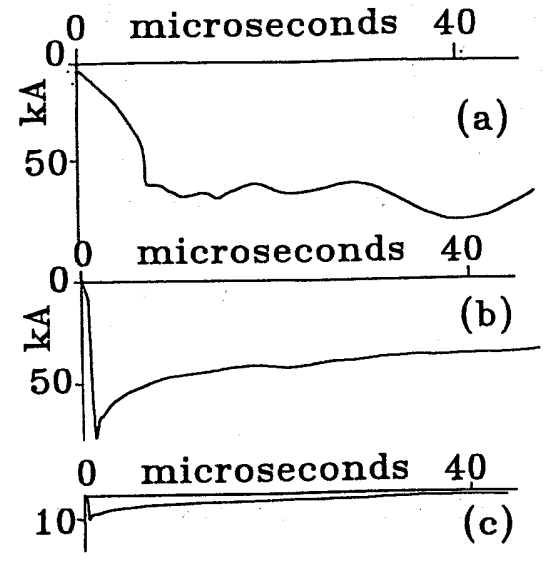

Figure 5 - Comparison of First and Subsequent stroke Waveforms

(a) First stroke

(b), (c) subsequent strokes 
set the same for Components $A$ and $D$ to enable indirect effects due to both rate of rise and peak amplitude to be evaluated by test or analysis methods employing a single component $A$.

Component $\mathrm{H}$ - Intracloud pulse. Component $\mathrm{H}$ represents one of the short duration, high di/dt current pulses that occur in intracloud flashes, particularly at initial leader attachment or formation (in aircraft triggered strikes) and also at other times during the flash. Such pulses are not often found in cloud-earth flashes and, until recently were not included in the aircraft lightning standards. Recognition of possible indirect effects due to their higher rates of change and the multiplicity of these pulses in a single flash led to the addition of the multiple burst environment to the aircraft standards in $1987[6,9]$. This environment is comprised of many component $\mathrm{H}$ pulses, as described later. The component $\mathrm{H}$ definition is typical of the intracloud pulses recorded by the NASA F106B research airplane $[12,13]$. Its peak $\mathrm{di} / \mathrm{dt}$ of $2 \times 10^{11} \mathrm{~A} / \mathrm{s}$ is among the higher rates recorded at the $\mathrm{F} 106 \mathrm{~B}$, although insufficient data exists to establish a severity percentage. The time durations of the highest recorded rates $\left(4 \times 10^{11} \mathrm{~A} / \mathrm{s}\right)$ were significantly shorter than the rise time $(0.1 \mu s)$ assigned to component $H$. Its decay time $(4 \mu s$ to 508$)$ is also longer than most recorded intracloud pulses.

Multiple Stroke and Burst Waveforms. The multiple stroke and burst waveforms are shown in Figures 6 and 7 and are intended for evaluation of avionic system upset possibilities. The multiple stroke definition

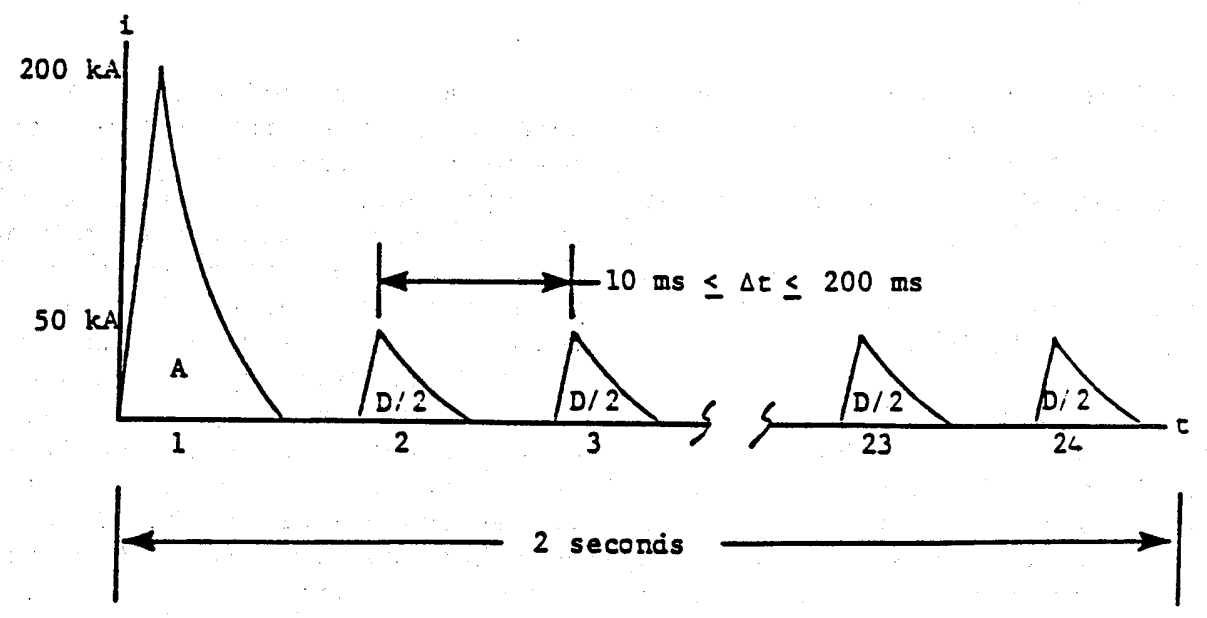

Figure 6 - Multiple Stroke Waveform

(One current component A followed by twenty-three current component $D$ 's at half amplitude distributed over a period of up to two seconds.) 


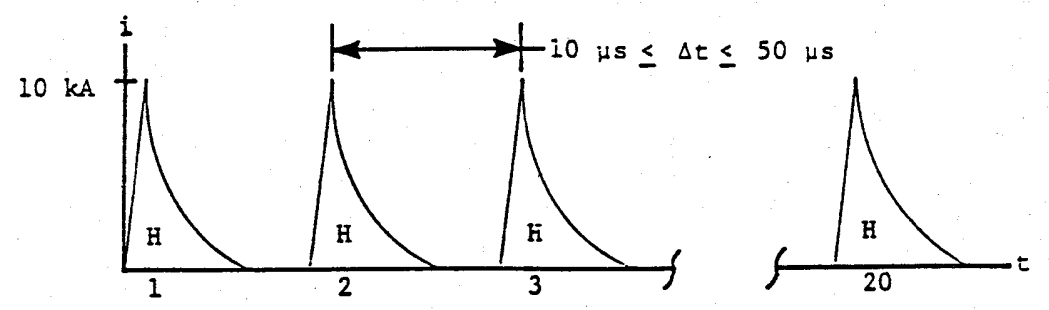

One burst is 20 pulses in I nillisecond

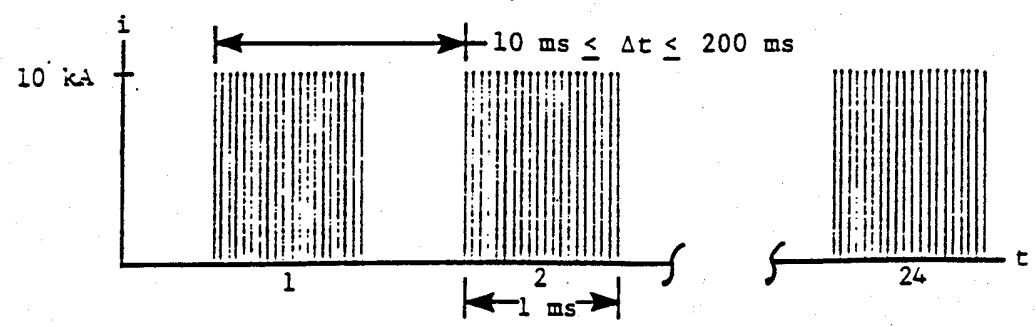

Twenty-four bursts distributed over a period of up to 2 seconds

Figure 7 - Multiple Burst Waveform

represents a near-maximum number of significant recorded pulses (24) in a cloud-earth flash, and employs the double exponential descriptions of components $A$ and $D$, with the $D$ amplitude being halved to avoid an unnecessarily severe combination. Whereas the amplitudes of subsequent strokes in naturally occurring flashes vary widely, only two amplitudes have been included in this definition for simplicity. Stroke separation is to be random but not less than $10 \mathrm{~ms}$ nor greater than $200 \mathrm{~ms}$, as shown in Fig. 6 . The multiple burst definition of 24 groups (bursts) of $20 \mathrm{H}$-pulses was derived from early interpretations of NASA F106B data which indicated similar groups of pulses throughout a flash duration of up to two seconds. Subsequent study has shown this may not be correct, however, and it is possible this definition may be modified in the future to incorporate fewer bursts. The waveform of component $\mathrm{H}$ pulses and number of them in a flash are likely to remain unchanged. Again, pulse and burst separation times are to be random but within the limits shown in Figure 7 .

\section{APPLICATION TO AIRCRAFT}

The voltage waveforms are applied to external surfaces of aircraft, especially extremities, to determine initial lightning attachment points and breakdown paths. Application is nearly always by test in which the specified voltages are applied between electrodes positioned adjacent the aircraft part and the tested part, which is usually at ground potential. specific test methods accompany the waveform definitions in $[5,7]$. 
The current components for evaluation of direct effects are applied to aircraft surfaces and other structural elements according to the zone(s) within which these elements are located. The aircraft lightning strike zones are defined as follows:

Zone $1 \mathrm{~A} \quad$ First return stroke zone with low probability of flash hang-on

Zone 1B First return stroke zone with high probability of flash hang-on

Zone $2 \mathrm{~A}$ Subsequent stroke zone with low probability of flash hang-on

Zone 2B Subsequent stroke zone with high probability of flash hang-on

Zone 3. No-strike zone, but through which lightning currents may be conducted between other zones.

Table 1 lists the components applicable to aircraft surfaces and structures within each zone. The locations of each zone on a particular aircraft depend on the aircraft geometry as well as its operational altitude and airspeed envelope. Methods for locating strike zones are included in the standards $[8,9]$ and have been the subject of recent discussion among aircraft lightning specialists. In particular, zone $1 \mathrm{~A}$ (which requires the first return stroke component) is now recognized to cover much greater surface areas than was traditionally expected $[14,15]$, and initial leader attachments are now known to occur at some aircraft flat surfaces as well as at sharp extremities. Figure 8 shows the lightning strike zones of a typical transport aircraft.
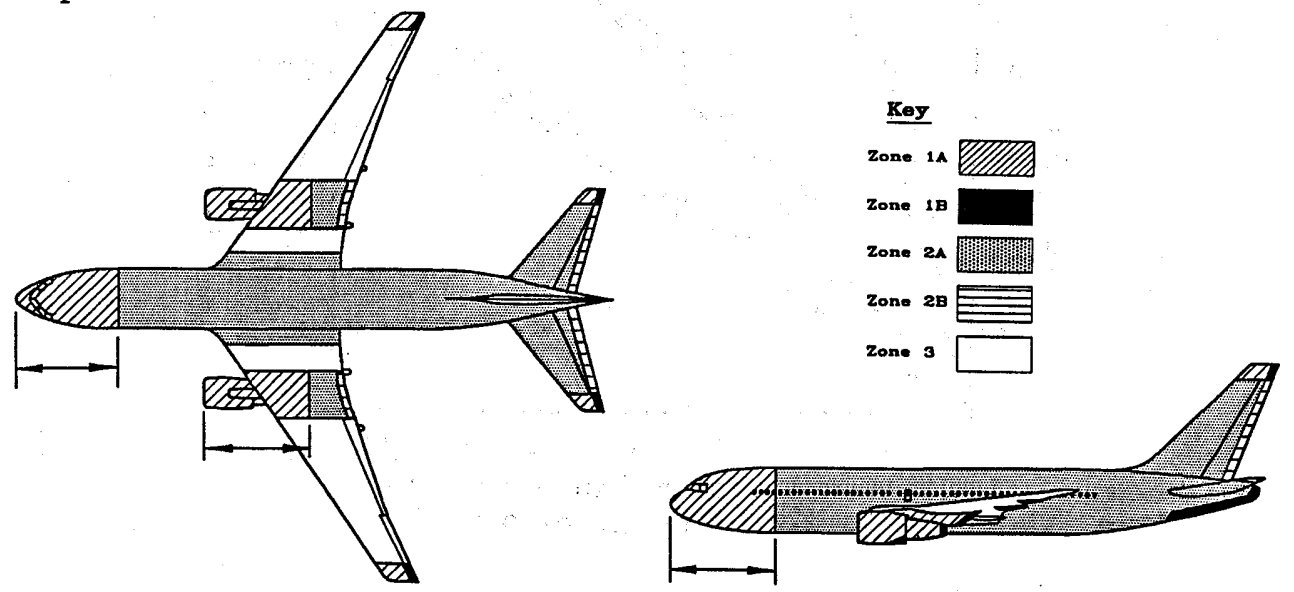

Figure 8 - Lightning Strike zones on Transport Aircraft 


\section{AREAS OF UNCERTAINTY}

Uncertainties exist in the degree to which some of the aircraft lightning standards faithfully simulate important effects of natural lightning, and these are the subject of present discussion and research. They are as follows:

Electric Fields Preceeding Lightning Attachment. These fields are presently represented by voltage waveforms $A$ and $D$. The uncertainty is because certain aircraft dielectric materials have responded differently to in-flight lightning than to laboratory applications of the standard waveforms. Diverter arrangements, for example, that successfully prevent punctures from tests have not always been successful in preventing punctures from in-flight strikes. The discrepancy may be due to other flight environmental factors, including water and ice, moving air, and ambient pressure. It may also be due to static E-field conditions that exist around an aircraft prior to the arrival of natural or aircraft triggered strikes. Tests at varying waveshapes have not, as yet, replicated all of the in-flight effects on certain aircraft radomes. Further research will be necessary, and the outcome may require simulation of other aspects of the flight environment.

Arrival Time of First Return Strokes at Flight Altitudes. Experience has shown that first return strokes, represented by Component $A$, often arrive at aircraft surfaces well aft of initial leader attachment points at forward extremities. A method has been formulated to estimate this distance, (d in Figure 8 ) based on aircraft altitude above ground (the shortest leader path between aircraft and earth) aircraft speed, and average leader velocity, assumed to be $1.5 \times 10^{5} \mathrm{~m} / \mathrm{s}[14]$. The method is illustrated in Figure 9. While the method does indicate the overall range of observed distances, $(1-6 \mathrm{~m})$, specific incidents do not seem to obey the relationship between altitude, airspeed and leader velocity assumed in Figure 9. The reason may simply be that leader velocities vary widely, and that leaders do not travel the shortest distance from aircraft to earth.

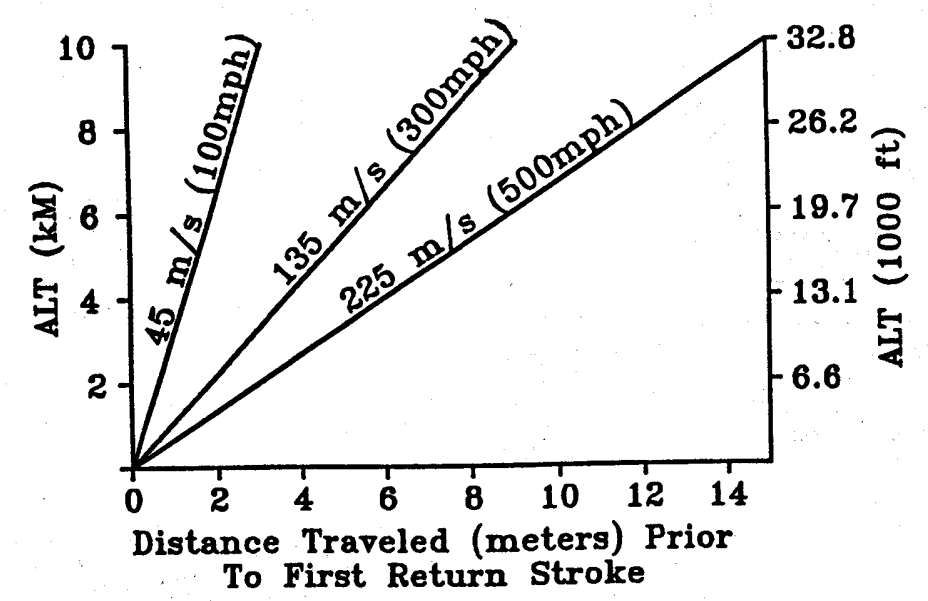

Figure 9 - Relationship of Leader Sweep Distance to Aircraft Speed and Altitude 
Transmission line models of cloud-earth return strokes predict a rapid reduction in return stroke amplitude (and action integral) with location in the channel above the earth; however, the severity of aircraft damage at flight altitudes up to $15,000 \mathrm{ft}$. indicates much higher than predicted amplitudes and action integrals. If the models are to be believed, the "starting point" stroke currents at earth must be substantially higher than statistics of ground flash data would indicate, and the frequent incidents of severe aircraft strikes seem incompatible with this.

Characteristics of Lightning in Non-Thunderstorm Clouds. Most statistics of natural lightning are based on data from the earth terminus of cloud-earth flashes originating in convective thunderstorms-mostly of the air-mass variety; yet a large portion of aircraft strike incidents undoubtedly occur in stratoform or other layered cloud situations, and also in low altitude cumulous type clouds which do not include freezing conditions. Some of these strikes produce severe damage, but no information is available on the currents involved. In a few cases, often involving strikes from low altitude clouds, the damage has been unusually severe and has been likened to "superbolts". Fortunately, no aircraft is known to have been lost as a result of such incidents, but proposals have surfaced for increasing the severity of the aircraft lightning standards. Before these are given serious consideration, more information is needed on the characteristics of this part of the lightning environment. 


\section{REFERENCES}

1. IEC 60-2, "High Voltage Test Techniques," Part 2: Test Procedures, Fig. 2, 3.

2. ANSI/IEEE Std. 28-1974, Fig. 3.

3. U.S. MIL-B-5087B, "Bonding Electrical, and Lightning Protection for Aerospace Systems and Hardware," Section 3.3.4.

4. U.S. FAA Advisory Circular AC 25-3/20-53, "Fuel System Lightning Protection."

5. SAE Committee AE4L Report, "Lightning Test Waveforms and Techniques for Aerospace Vehicles and Hardware," June, 1978.

6. SAE Committee AE4L Report, "Recommended Draft Advisory Circular Protection of Aircraft Electrical/Electronic Systems Against the Indirect Effects of Lightning," October, 1989.

7. U.S. MIL-STD-1757, "Lightning Test Waveforms and Technqiues for Aerospace Vehicles and Hardware."

8. U.S. FAA Advisory Circular AC 20-53A, "Protection of Airplane Fuel Systems Against Fuel Vapor Ignition due to Lightning," April, 1985.

9. U.S. MIL-STD-1795, "Lightning Protection of Aerospace Vehicles and Hardware" June, 1989.

10. Cianos, N. and Pierce, E. T., "A Ground Lightning Environment for Engineering Use," Technical Report 1, Prepared by Stanford Research Institute for the MCDonnell Douglas Astronautics Company, Huntington Beach, CA, August 1972 .

11. Andersen, R. B. and A. J. Eriksson, "Lightning Parameters for Engineering Applications," International Conference on Large HighTension Electric Systems (CIGRE) Study Committee 33 Document 33-79 (SC) 04 IWD.

12. Pitts, F. L., L. D. Lee, R. A. Perala and T. H. Rudolph, "New Results for Quantification of Lightning/Aircraft Electrodynamics," J. of Electromagnetics, Vol. 7, 1987.

13. Pitts, F. L., G. B. Finelli, R. A. Perala and T. H. Rudolph, "F-106 Data Summary and Model Results Relative to Threat Criteria and Protection Design Analysis," Proc. of the Int. Aerospace and Ground Conf. on Lightning and Static Electricity, Dayton, Ohio, June 1986.

14. Plumer, J. A., "Further Thoughts on Location of Lightning Strike zones on Aircraft," Proceedings of International conference on Lightning and static Electricity, 1980.

15. Plumer, J. A., "Examples of Severe First Return Stroke Arrivals Aft of Aircraft Forward Extremities," Proceedings of International Conference on Lightning and Static Electricity, 1989. 